IRA-International Journal of Management \& Social Sciences

ISSN 2455-2267; Vol.03, Issue 03 (2016)

Institute of Research Advances

http://research-advances.org/index.php/RAJMSS

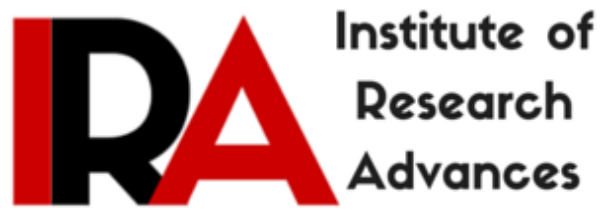

\title{
Trends in Regional disparity of Southern states in India during the Post-reform period
}

\section{Dr. Muthumurugan. $\mathbf{P}$}

Assistant Professor of Economics,

Thiruvalluvar College, Manonmaniam Sundaranar University, Papanasam, Tirunelveli-627425, Tamilnadu, India.

Ganesasubramanian. R

Ph.D-Scholar, Department of Economics, Pondicherry University, Puducherry-605014, India.

DOI: http://dx.doi.org/10.21013/jmss.v3.n3.p28

\section{How to cite this paper:}

P, M., \& R, G. (2016). Trends in Regional disparity of Southern states in India during the Post-reform period. IRA-International Journal of Management \& $\begin{array}{llll}\text { Social Sciences } & \text { (ISSN } 2455-2267), & \end{array}$ doi:http://dx.doi.org/10.21013/jmss.v3.n3.p28

(C) Institute of Research Advances

\section{(cc) EY-NC}

This works is licensed under a Creative Commons Attribution-Non Commercial 4.0 International License subject to proper citation to the publication source of the work.

Disclaimer: The scholarly papers as reviewed and published by the Institute of Research Advances (IRA) are the views and opinions of their respective authors and are not the views or opinions of the IRA. The IRA disclaims of any harm or loss caused due to the published content to any party. 


\begin{abstract}
Regional disparity is a crucial problem. It has attained so much of concern from classical economists to recent development researchers and that has been creating more dilemmas among the planners to make plan for reducing the imbalances. Hitherto in India most of the studies have been identified the backwardness across the nations as well as states by different development index analysis and these studies were more ideal in the sense of disparity and they are found to be giving no clear picture about regional disparities and were not comprehensive in nature but only isolated manner. Within this premises, this paper tries to make an attempt to analyze the trend in regional economic disparities in economic growth of Southern states in India during the post reform period from 1991-92 to 2011-12 by measure of Hauser's Index of relative economic growth.
\end{abstract}

Keywords: Backwardness, Balanced regional development, Gross State Domestic Product, Index of relative economic growth, Regional disparity

\title{
JEL Classifications: R11, O181
}

\section{Introduction}

Balanced regional development is a multifaceted issue in every developing and developed country. The regional disparities arise from some economic lacks and advantages from the natural resources with manmade in the sense that an investment benefits. There is much a focus on the issue of regional disparities from the classical economists to recent development researchers and they were given some ideas to how regional imbalances arose, how to measure and how to reduce the increasing disparities. The regional imbalances usually results in underutilization or even non-utilization of natural and human resources. As a result, gab between lagging region and developed region goes on widening and this may generate the tension which may inhibit the process of economic development. The reasons for these disparities may be happening to be three: one, historical growth based on natural advantages, two, non- uniform distribution of natural resources and three, high concentration of resources. Identifications of backward regions and developed regions in terms of economic development are significant. Thus, to fix the exact techniques to identify the backward province among region are essential among the planners. Notwithstanding, there have been more clue and ideas given to measure and identify the regional imbalances despite the regional disparities may widen time to time. This may be because lack of appropriate policies with exact identification of regional disparities. Consequently in this context, the study main focuses on this issue and it does not go into find the reasons for that and only analyze to review and trends of regional disparities in economic growth of the southern states in India over a post-reform period.

\subsection{Background}

There are more appropriate solutions to reduce the increasing regional disparities in economic development by the researchers despite in Indian context its widening regional disparities. Considerably there are quite number of studies have tried to reduce the economic disparities. For instance; Nair [2004] has compared regional disparities in economic growth and employment. He has given the solution to reduce these disparities by providing infrastructural facilities. Prem Narain [2004] analyzed hilly states in India by using composite index analysis. It found that socio-economic development is highly associated with infrastructural facilities, literacy rate and wide disparities in the levels of economic development have been observed among different states. Bhattacharyya and Sakthivel [2005] assessed the regional growth and disparity in India. It is observed that regional disparity has widened significantly during 1990s. 
Accordingly we observed from the previous studies, they took major states or entirely by measures of convergent- divergent and spatial analysis. Thus, the identification of backwardness is important to reduce the regional disparities. So, it is difficult to be identified by taking entire states but can be possible at only some province of the country, which leads to easily identify the regional disparities. Therefore, the present paper makes an attempt trends in regional disparities in economic growth with takes only a southern part of Indian during the post reform period.

\subsection{Literature review}

Considerably a large number of researchers have tried to find out the extent of regional disparities in economic growth and development. It begins with our reach to review whole the literature in the concerned direction. However an attempt has been made to sieve out the important work in this direction. For instance; Francois Perroux [1955] in his growth pole theorem made clear the fact that "growth doesn't appear everywhere at the same time, it spreads by different channels and with variable terminal effects for the economy as a whole". One of the important theories of regional disparities is the "Concentration-cycle hypothesis" developed by Myrdal [1958], Hirschman [1958], Williamson [1965] and Alonso [1968]. This hypothesis states that regional disparities diverge initially and classifies the forces of divergence as backwash effects and the forces of convergence as spread effects. Myrdal concentrates his attention on the divergent phase. Myrdal hypothesized the cumulative causation. He pointed out that economic and social forces will create cumulative expansion in the favored multiplier effect will -cause increasing return in one region at the expense of surrounding region. Alonso also keeps the same view and holds that the emergence of town and its growth as a feature of divergent phase. Myrdal [1958] and Kaldor [1960] feel that the basic forces inducing development are disequilibrating in nature. Once the process of divergence is started often it will be further accelerated as a result of new development. Myrdal recognizes that the sprees effects are stronger when the economy develops and the backwash effects are more powerful than the spread effects in the beginning. Sudhakar Reddy [1995], in his paper tries to identify the backward state or region in India on the basis of sectoral income in the state net domestic product. For this purpose he takes two periods i.e. 1981 and 1989 covering 5th and 6th Five Year Plans. The study takes 1981 as base period because data of the state net Domestic product is available in 1980-81prices. The study considered a state as the one, whose proportions of tertiary sector income in State Net Domestic Product [SNDP] is lower than all India average tertiary sector income. Dipankar Dasgupta [2000] has analyzed growth and interstate disparities in India. The study given analytical description of the economic performance of Indian states as reflected in their per capita state domestic product. The study has used simple statistical analysis for the period of 1960-61 to 1995-96.Finally the study has found clear tendency for the Indian states to have diverged during post reform period. Nair [2004] has examined economic reforms and regional disparities in economic and social development in India. The study compared of the results regarding the relationship between the growths of NSDP and employment at the regional level, in the pre and post reform periods give a broad indication about such a logical connection, while growth of employment and of NSDP had a positive and significant correlation in the pre-reform era. In the agricultural sector, there is no evidence of any inter-state convergence in the post-reform era. The study suggested that infrastructural development is of great help promoting regional development. Prem Narain, et.al. [2004] have analyzed the socio-Economic development of hilly states in India. They have used Composite index of Development for 17 variables with 11 states. The study has found that the socio-economic development is highly associated with infrastructural facilities and literacy rate and wide disparities in the level of development have been observed among different states. Finally the study has found that the positive relationship between developments in infrastructural facilities and overall economic fields. Rajasekhar and Gagan Bihari Sahu [2004] have analyzed the growing rural-urban disparities. The study has used NSSO data and this study examined on previous study about regional disparities what they have analyzed and their used methodologies. 
They have suggested that income is not a sufficient indicator to capture the magnitude of disparities at any level and it is therefore necessary to develop some other indicators representing human resource development and infrastructural facilities to understand the growing rural -urban divide. Bhattacharya and Sakthivel [2005] have assessed that the regional growth and disparity in India. The study has compared the pre and post reforms period. The regional disparity has widened significantly during 1990's. The authors have found that the growth performance and structural change in the State Domestic Production [SDP] of nation's states in two periods reveals that the development process has been uneven across the states. While the advanced states have tended to leap frog in the reform years, other states have lagged behind as they have higher population growth and lower income growth and could tend to have higher unemployment rate.

\subsection{Objectives and Chapter design}

The main objective of this paper is to analyze the trend in regional disparities in southern states of India during the post reform period from 1991-92 to 2011-12. This paper has four sections; the first section reveals that introduction with background, literature reviews and objectives. The second section deals with data and Methodology. The third section deals with results and discussions and final section deals with conclusion.

\section{Data and Methodology}

The study makes an attempt to analyze the recent trends in regional disparities in Southern states [Andhra Pradesh, Karnataka, Kerala and Tamil Nadu] of India during the post reform period from 1991-92 to 2011-12. The study entirely based on secondary data. The required data for the analysis were collected from CSO, Economic Survey and RBI. For analyzing the recent trends in regional disparities of southern states in India by used State Domestic Product [SDP] and GDP based constant price 2004-05. The paper attempts to analyze the regional disparities through simple statistical techniques. And to find the relative economic growth based on Hauser's index. Also a very simple index advocated by Hauser and later used by Radha Devi [1995] after her study and Anvar [2003] way of relating to population and economic growth will be used in this paper. Here is an attempt to assess the economic performance of the State in India with respect to their 'State Domestic Product' [SDP].

In this method the Index of Relative growth [IRG] is computed. It is the ratio which is expected to show in percentage terms whether a State's contribution to National Domestic Product [NDP] is higher or lower in comparison with its contribution to National population. A ratio of one hundred will be interpreted as equal contribution by the National Domestic Product [NDP] and population whereas a ratio above one hundred will be interpreted as higher contribution to the State Domestic Product[SDP] than its contribution to population and vice versa.

Where

$$
\text { The formula used is }{ }_{\text {IRG }}=\sum_{i=1}^{n}\left(\begin{array}{c}
\frac{\mathrm{W} 1}{\mathrm{~V}} \\
\mathbf{P} / /
\end{array}\right) * \mathbf{1 0 0}-\mathbf{1 0 0}
$$

$$
\begin{array}{ll}
\mathrm{Yi} & - \text { SDP of ithState } \\
\mathrm{Y} & - \text { GDP } \\
\mathrm{Pi} & - \text { Population of } \mathrm{i}^{\text {th }} \text { State } \\
\mathrm{P} & \text { - National population }
\end{array}
$$

\section{Results and Discussion}

The present section of this paper has been discussed with the results of data analysis. The performance of Southern states in terms of economic growth i.e. State Domestic Product [SDP] during the post reform period. 


\subsection{Growth Performance of Sectoral Income [NSDP] in Southern States of India at Constant Prices during Post-reform Period}

The economic importance of these southern states of the union has been contributed more than their size and population. These states are accounted 20 per cent of geographical area and 20.77 per cent of population in 2011. The share in aggregate gross domestic product in India [GDP] has significantly improved with slight fluctuations over the three decades from 23 per cent in 1980-81 to 27 per cent in 2000-01 and to about 25.05 per cent in 2011-12; it's almost equal to the northern and Himalayan states. During the post reform period the southern states are achieved exciting average growth rate compared at national level, moreover on all social indicators these all four states were above national average. The annual growth of sectoral income of the southern states in India has been discussed below:

\section{Andhra Pradesh}

The compared with annual NSDP sectoral growth of Andhra Pradesh, the agricultural sector is an outstanding performer and which gives a large share to enhance the overall GSDP. The industrial sector and service sector remains in the same position in their growth. But agriculture sector has to further strengthen; it has not received inadequate priority in the past two decades. The state need to further improve in infrastructure facility to attract FDI. To restore community development, employment should be generated through labour-intensive growth. The overall reform initiatives had been better in the case of Andhra Pradesh however some areas still needs to be addressed namely agriculture and infrastructure. However, comparatively the performance of agricultural sector is better concentration in Andhra Pradesh [See the figure.1].

\section{Karnataka}

The sectoral growth of Karnataka from 1991-92 to 1997-98for three sector were similar position after that they were goes on different path. The traditional sector has down as negatively during 2001 to 2005 due to the natural factor like drought but 2004-05 its growth was very higher than the other sector. The industrial sector growth has significant up to 2009-10 and after its growth has grown negatively but the service sector has same path. Its growth has witnessed that during post-reform period the states that were severally attracted by foreign investment. It exhibits that direct link with foreign trade [See the figure.2]. Thus, Compared with three sectoral income growths, the agricultural and service sector have observed high concentration to GSDP growth.

\section{Kerala}

Considerably, Kerala is a superior concentrator of its own economic growth in terms of Per capita income and HDI. The growth performance of sectoral income have grown similar path up to 2004-05. In 2006-07 the agricultural sector has decreased with negatively and industrial sector has grown positively [See the figure.3]. Thus, the growths of all sectors, except agricultural sector, are similar and the state has high concentration on secondary and territory sector during post reform era. During Post reform period amongst the major richer states Kerala attracted considerable investment to start small and medium scale industries.

\section{Tamil Nadu}

The performance of sectoral income growth during the post reform period, the agricultural and industrial sector both were decreased in 2002-03 but the service sector comparatively remain achieved consistent growth, it has witnessed growth [see the figure .4]. Thus we are observed from the annual growth of NSDP of sectoral growth, the share of service sector is significant contribution to the GSDP in Tamilnadu.. 


\subsection{GSDP in Southern States of India}

GSDP is an important component of enhance the state economic growth. We have observed from the figure 3.5 that the growth performance of GSDP in southern states in Indian economy. The state of Tamil Nadu is low growth compared to its neighboring states, it followed by Andhra Pradesh and Karnataka. The state of Kerala is comparatively high in its growth during the post reform period.

\subsection{Index of Relative Economic growth}

The Index of Relative Economic growth examines how contribution of each state in the country towards economic growth compared with its contribution to population. The IREG computed for the southern states in India for 1991-92 and 2011-12 given in the table.1.

The economic growth disparity in southern states of India has observed with the help of IREG. It is found that the value of IREG for two bench mark year [i.e. post reform period] during 1991-92 to 2011-12. In 1991-92, Tamil Nadu was better performer to the contribution of national growth along with Andhra Pradesh. They had been secured 1st and 2nd rank with the value of IREG 140.24 and 3.19 respectively.

In respect of value of IREG in 2011-12 Andhra Pradesh has secured first position with value 214.10 and Tamil Nadu also had been second rank with 22.16[See also figure.5].Thus we have compared with an overall period for the southern states in India. Andhra Pradesh and Tamil Nadu are better in respect of their economy.

\section{Conclusion}

This paper has analyzed the recent trends in regional disparity in Southern states of India during the post reform period. The spacious disparity is observed among the southern states of India from the results of IREG. While compared with inter-state level, Andhra Pradesh and Tamil Nadu have topper in respect of their economic growth, because these states may be they are proper public investment and policies have been maintaining. Moreover, the states of Karnataka and Kerala have comparatively their growth fairly but we cannot say as well, however there is a good public investment climate in all southern states except Kerala. Albeit, these state governments have to concentrate more on their economic growth. Finally, this paper suggests that if the government should have more concentrated on public investment, it will help to reduce regional disparity in terms of economic growth.mic growth. They have more concentration on three sectoral growths.

\section{References}

\section{Articles}

Rao, Hanumantha, C.H., and Dev, S.Mahendra [2000]: "Economic Reforms and Challenges Ahead: An Overview", Economic and political weekly, Pp.1130-1141.

Singh [2012], "Regional disparities in the post reform period" Journal of regional development and planning, Vol. 1,

Dipankar Dasgupta [2000] et.al. "Growth and Inter-state Disparities in India", Economic and Political Weekly, Vol. 35, No. 27, pp. 2413-2422.

Kumar, Utsav and Subramanian [2012] "Growth in India's States in the First decade of the 21st Century: Four Facts” Economic and Political Weekly, Pp.48-57.

Prem Narain., Sharma, S.D., Rai, S.C. and Bhatia,V.K. [2004]. Estimation of socio-economic development in hilly states. J. Ind. Soc. Agri. Statistics. 58, 126-135.

\section{Books}

Chandhrasekara, C.S. 1970 Balanced Regional Developments Problem and Prospects in T. B. Lahiti [ Ed] No.1.p.40 
Francois Perroux.1955, "Notes on the concept of growth pole", I.M.Livingston[Ed], Development of Economics and Policy-Readings G.Allien \& Unwin, London.

Friedman.J and Alonso.W, 1964, "Regional Development Planning; A Reader", M.I.T Press, Cambridge.

Gandhi, Indhira in her address to the National Development Council [NDC] in April 1969.

Hirschman, A.O, 1958, The Study of Economic Development, Yale University press.

Kaldor, 1960, A Model of Economic Growth, Gerald Duckworth and company Limited, London.

Myrdal Gunnar, 1958; Economic Theory and Under Developed Regions, Vora, Bombay Sudhakar Reddy. B. 1995, "Regional variations in Sectoral Distributions of Income, Susheela Subramanya, M.V.Srinivas Gowda[Ed],Regional Economic Developmet in India Deep and Deep Publication.

Radha Devi 1995, "Population and Relative Economic Growth: Experience of Different States", Susheela Subramanya and M.V.Srinivas Gowda [ED], Regional Economic development in India, Deep and Deep Publications, New Delhi.

Williamson J.G., 1965 "Regional Inequality and the Process of National Development "Economic Development and Cultural change, Vo1.30, No. 4.

\section{Web sources}

http://planningcommission.nic.in/reports/sereport/ser/stdyerrd.pdf

\section{Unpublished thesis}

Anvar.P [2003] "Regional Development in Kerala: A study of Malappuram District", Unpublished $\mathrm{PhD}$ - Thesis, Cochin University of Science and Technology, Kerala, India. 


\section{Appendix}

Table.1 Ranks for the IREG in Southern states of India

\begin{tabular}{|l|c|c|c|c|}
\hline \multicolumn{1}{|c|}{ State } & $\begin{array}{c}\text { IREG } \\
(1991- \\
92)\end{array}$ & Rank & $\begin{array}{c}\text { IREG } \\
(2011- \\
12)\end{array}$ & Rank \\
\hline $\begin{array}{l}\text { Andhra } \\
\text { Pradesh }\end{array}$ & -3.19 & 2 & 214.10 & 1 \\
\hline Karnataka & -24.43 & 3 & -8.24 & 4 \\
\hline Kerala & -35.02 & 4 & 5.76 & 3 \\
\hline Tamil Nadu & 140.24 & 1 & 22.66 & 2 \\
\hline
\end{tabular}

Figure. 1

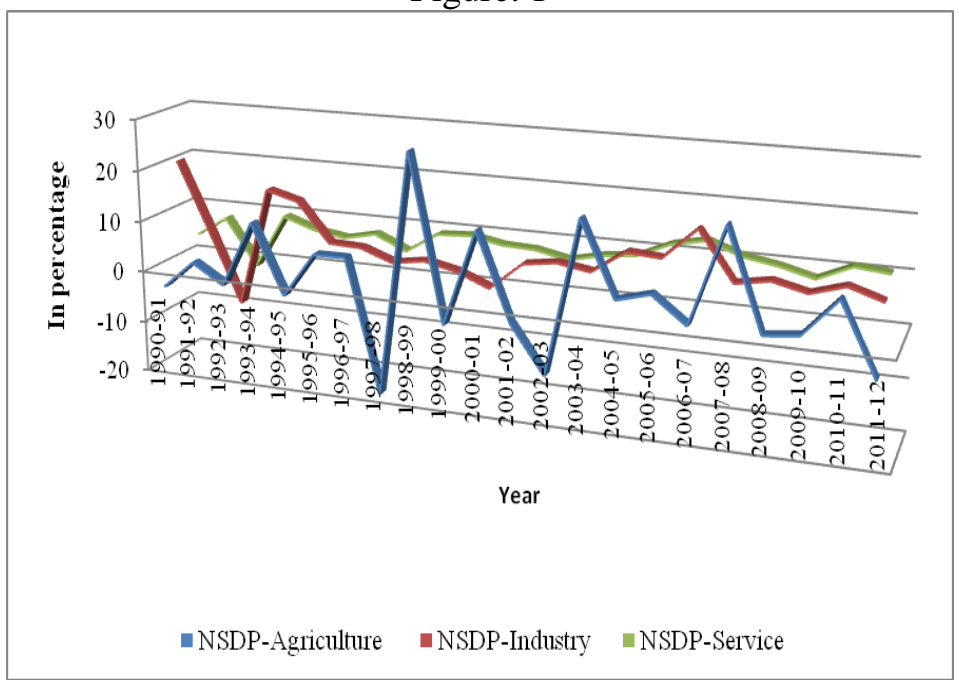

Figure.2

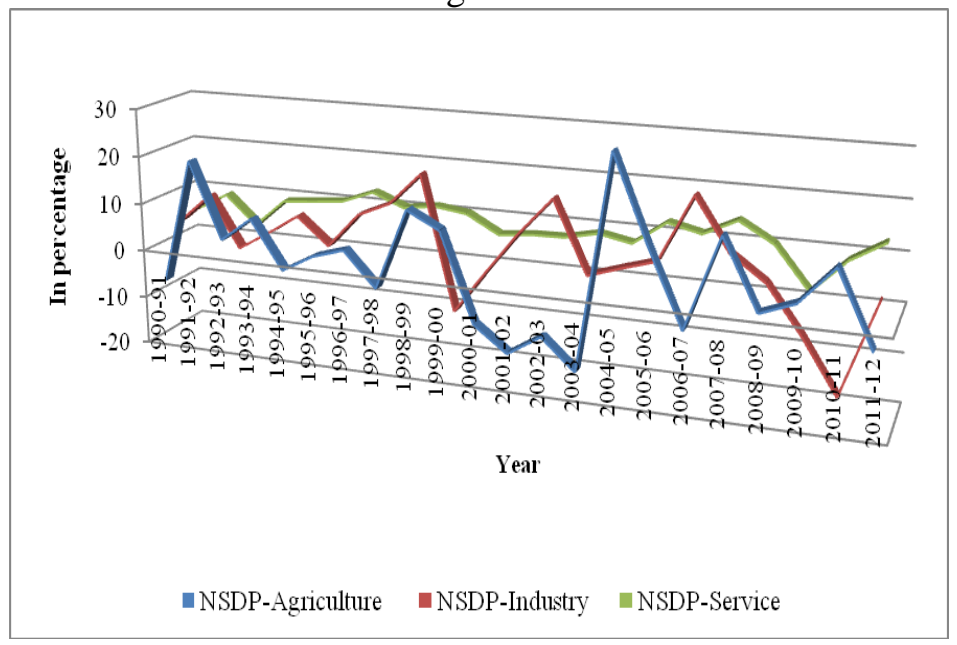


Figure.3

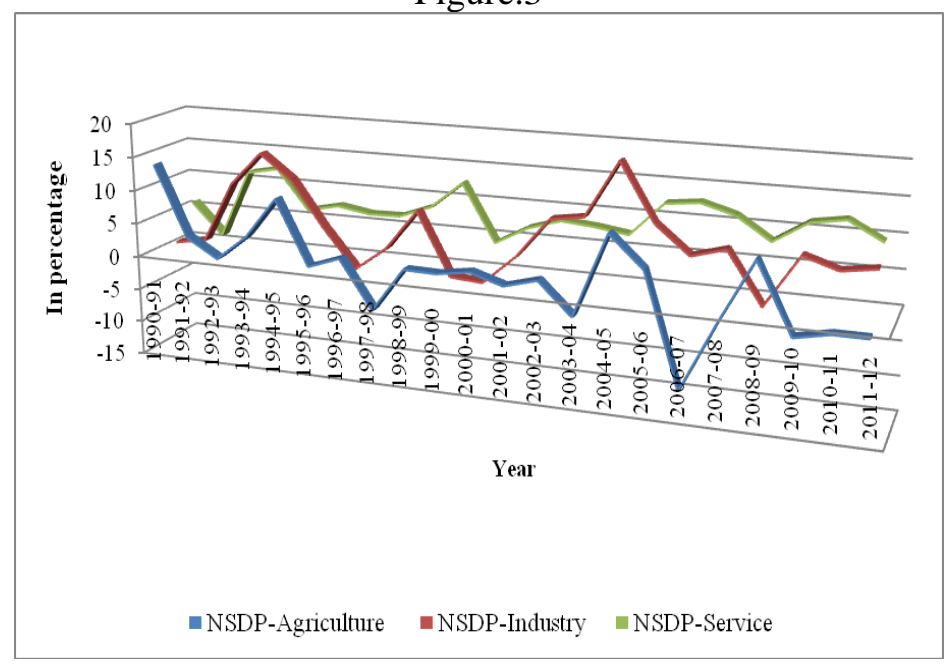

Figure.4

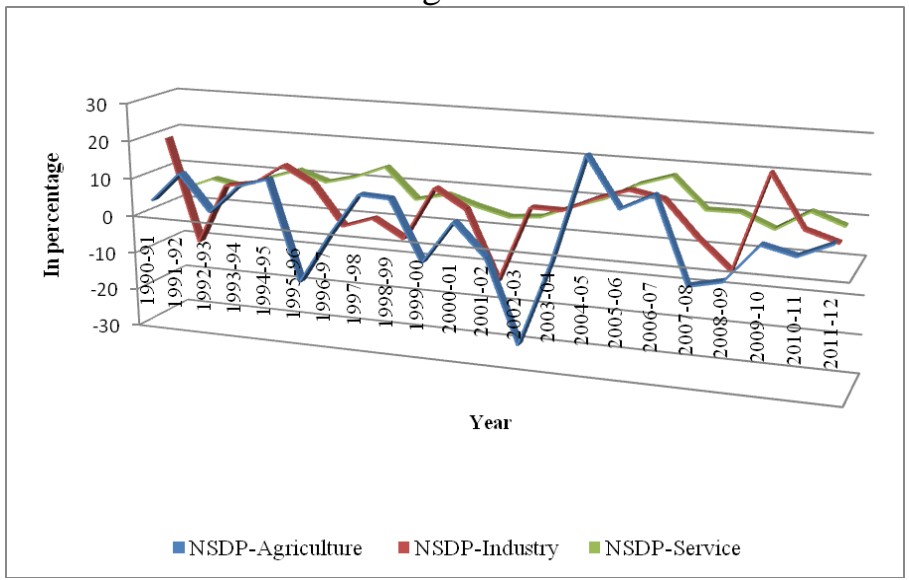

Figure.5

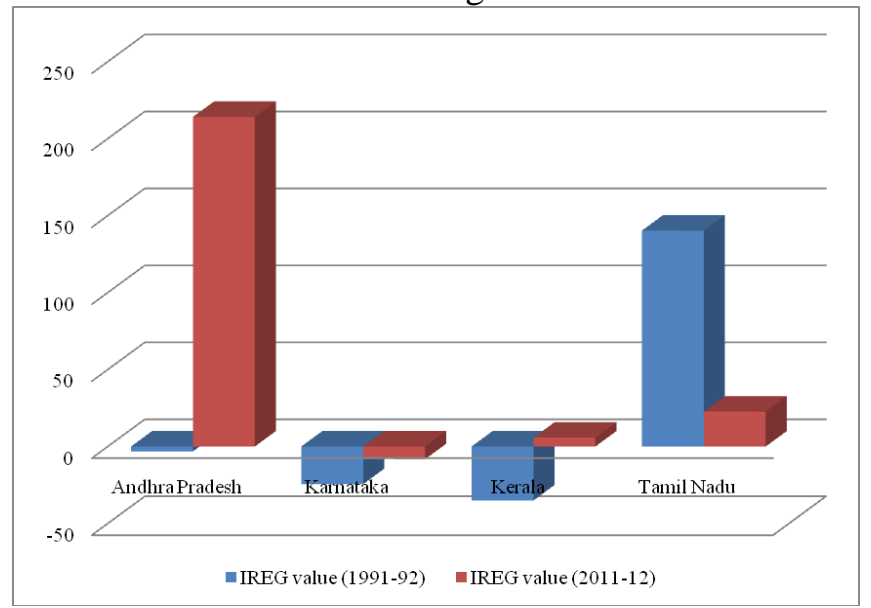

